\title{
Improving Carbon Mitigation Potential through Grassland Ecosystem Restoration under Climatic Change in Northeastern Tibetan Plateau
}

\author{
Lin Huang, Xinliang Xu, Quanqin Shao, and Jiyuan Liu \\ The Institute of Geographical Sciences and Natural Resources Research, Chinese Academy of Sciences, Beijing 100101, China \\ Correspondence should be addressed to Xinliang Xu; xuxl@lreis.ac.cn
}

Received 14 February 2014; Accepted 2 April 2014; Published 8 May 2014

Academic Editor: Dong Jiang

Copyright (C) 2014 Lin Huang et al. This is an open access article distributed under the Creative Commons Attribution License, which permits unrestricted use, distribution, and reproduction in any medium, provided the original work is properly cited.

\begin{abstract}
To protect the water tower's ecosystem environment and conserve biodiversity, China has been implementing a huge payment program for ecosystem services in the three rivers source region. We explored here the dynamics of grassland degradation and restoration from 1990 to 2012 and its relationships with climate mitigation in the TRSR to provide a definite answer as to the forcing and response of grassland degradation and restoration to climate change. Then we estimated its potential of climate mitigation benefits to address the question of whether ecological restoration could be effective in reversing the decline of ecosystem carbon mitigation service. The trend of average annual temperature and precipitation observed by meteorological stations were approximately increased. Compared before and after 2004, the area of grassland degradation was increased slightly. However, nearly one-third of degraded grassland showed improvement, and the grassland vegetation coverage showed significant increase. Comparing current grassland vegetation coverage with healthy vegetation cover with the same grass type, nearly half of the area still needs to further restore vegetation cover. The grassland degradation resulted in significant carbon emissions, but the restoration to its healthy status has been estimated to be technical mitigation potential.
\end{abstract}

\section{Introduction}

Ecosystem degradation is causing decline in ecosystem condition and widespread biodiversity loss, leading to reduced provision of ecosystem services [1-3], and may cause the irrevocable loss of ecosystem functions such as soil and soil moisture retention, regulation of water flows, and regulation of carbon and nitrogen cycles [4,5]. Ecological restoration is regarded as a major strategy for reestablishing and increasing the provision of ecosystem services as well as reversing biodiversity losses $[3,6]$, but conflicts can arise, especially if single services are targeted in isolation, and the recovery can be slow and incomplete [3]. In addition, a lack of scientific understanding of the factors influencing provision of ecosystem services and of their economic benefits limits their incorporation into land-use planning and decision making $[7,8]$.

The many ecosystem services from grasslands will be valued variously by different stakeholders, in which local stakeholders may tend to value productive services and specific ecosystem services such as hydrological services, while international valuations may apply to niche products or for biodiversity conservation services [5]. However, there are usually trade-offs between the different ecosystem services targeted [9]. Restoration of converted grasslands may improve ecosystem services functioning $[10,11]$, in some cases to levels comparable with nondegraded grasslands, but may not be able to fully restore ecosystem service provision to that of natural grassland $[10,12]$.

Change in vegetation cover at landscape scale has potential to influence regional climate [13], which may be larger than the effects of global climate change [5]. Various methods of improved grassland management can sequester carbon in soils [14] and in below- and aboveground biomass [15]. Compared to other mitigation options, grassland mitigation is cost-competitive $[16,17]$. Climate change mitigation services in grasslands may provide an entry point to the valuation of grasslands for their conservation and restoration. 
Globally, grazing land management has been estimated to have a technical mitigation potential of $1.5 \mathrm{GtCO}_{2} \mathrm{eq}$ p.a. to 2030 [5]. Degraded grasslands may have significant potential for carbon sequestration [18], through protection and restoration of grasslands. Unfortunately, data on the restoration potential of degraded grassland is not available. Systematic documentation and analysis of costs of protecting and restoring grasslands are still limited [5].

More analysis and evidences are crucially required to provide a definite answer as to the forcing and response of grassland degradation and restoration to climate change and its potential of climate mitigation benefits. Here, we explored in detail the dynamics of grassland degradation and restoration and its relationships with climate mitigation in the TRSR. Specifically, we ask the following questions: (1) how to analyze the dynamics of grassland degradation and restoration under the climate change? (2) Whether ecological restoration could be effective in reversing the decline of ecosystem carbon mitigation service? (3) Will a focus on the ecosystem service enable providing a mechanism for their potential climate benefit?

\section{Methods}

2.1. Study Area. The TRSR (Figure 1), covering 0.36 million $\mathrm{km}^{2}$, is located in the northeast of the Tibetan Plateau. It is the source region of the Yangtze River, the Yellow River, and the Mekong River and also one of the most important biodiversity hotspots in China. Glaciers, permafrost, and snows are widespread here owing to its average altitude of above 4,000 meters and annual temperature of $-5.6 \sim-3.8^{\circ} \mathrm{C}$. It is also regarded as a gene bank of 2,238 rare species of vascular plateau plants and suitable habitat for more than 400 endangered animal species. Nearly 600 million people who live downstream depend on the proper functioning of the rivers in this region for their livelihood. About 0.6 million people live in the region, in which $68.15 \%$ are herders. The Sanjiangyuan National Nature Reserve (SNNR) located in TRSR is the highest and most extensive wetland protected area in the world and has an area of 0.15 million $\mathrm{km}^{2}$, which could be divided to 6 subareas and consists of 18 conservation areas. Since 2005, $\$ 7.5$ billion yuan (US $\$ 924.79$ million) was provided by Chinese government to conserve and restore the ecological environment in SNNR, with a focus on alpine swamp meadow and natural habitat of the unique wildlife.

2.2. Grassland Vegetation Coverage. Vegetation coverage is one of the most important indicators to measure the status of land surface vegetation, and its changes reflected the growing conditions of the vegetation. In this paper, the semimonthly $1 \mathrm{~km}$ NOAA-AVHRR (1990-2000) and $1 \mathrm{~km}$ SPOTVGT (1998-2012 years) were collected as the data source. We produced the annual maximum NDVI values through maximum value composite (MVC). The linear regression analysis and correlation analysis were processed in overlap years (1998-2000) of AVHRR and VGT by pixel average, and linear regression relationships between AVHRR and VGT data for the three years were established. The AVHRR data were corrected grid by grid applying these relationships.
And then we applied $1 \mathrm{~km}$ NDVI data products to calculate and analyze annual average maximum vegetation coverage in the periods before (1990-2004) and after (2004-2012) the implementation of ecological conservation program in TRSR, to show the vegetation growing recovery and/or deterioration.

To illustrate the potential of vegetation growing in this area, we have produced the vegetation coverage distribution map of healthy grass ecosystem, which was extracted from average coverage of typical grass lawn in same zonal groups according to the type of "Qinghai Grassland Survey." We considered that the healthy vegetation coverage with the same grassland type is future recovery goals that we could achieve.

2.3. Grassland Degradation and Restoration. The remote sensing classification system of grassland degradation in TRSR, according to the principles and characteristics of remote sensing image interpretation, and based on a Chinese national standard "the grading index of natural grassland degradation, desertification, salt marshes (GB19377-20031)," was applied to interpret the trends of grassland degradation by remote sensing. The main data sources were MSS in the 1970s, TM in 1990, and TM/ETM in 2004. Images were acquired concentrating on July and August. And false color composition, geometric correction, images mosaic, and segmentation were processed. The outline of grassland degradation type was delimited by comparison of images in different time periods, with the references from the former. By visual interpretation, we produced the grassland degradation conditions and trends in the periods of 1970s1990 and 1990-2004 in TRSR.

In order to reflect the changing trend of grassland ecosystems more accurately, especially improved and restored grassland, we developed the change trend classification system of degraded grassland, based on the status of grassland degradation. Based on the remote sensing interpretation map of grassland degradation in the periods of 1990-2004, we produced change situation map of degraded grassland ecosystem from 2004 to 2012, by comparing TM or ETM remote sensing images in 2004 and 2012, which consists of new occurring degradation, intensified degradation, nonchange, slight restoration, and substantial slight restoration. According to the change information of degraded grassland, we determined the growth variation of grassland vegetation.

2.4. Climate Change Factors Analysis. The TRSR has few national and local stations with weather records spanning 1960 s to present. For the long-term meteorological station, we obtained daily data sets of thirteen national stations, including daily maximum and minimum air temperature, air pressure, daily total water equivalent precipitation, relative humidity, snow depth, and evaporation from China Meteorological Bureau. The temperature and rainfall data sets of well-distributed sites were interpolated by the software ANUSPLIN, which considered the impacts of terrain factors and was suitable for long-term observed data.

The moisture index equals the ratio of annual precipitation and annual potential evapotranspiration (PET). 

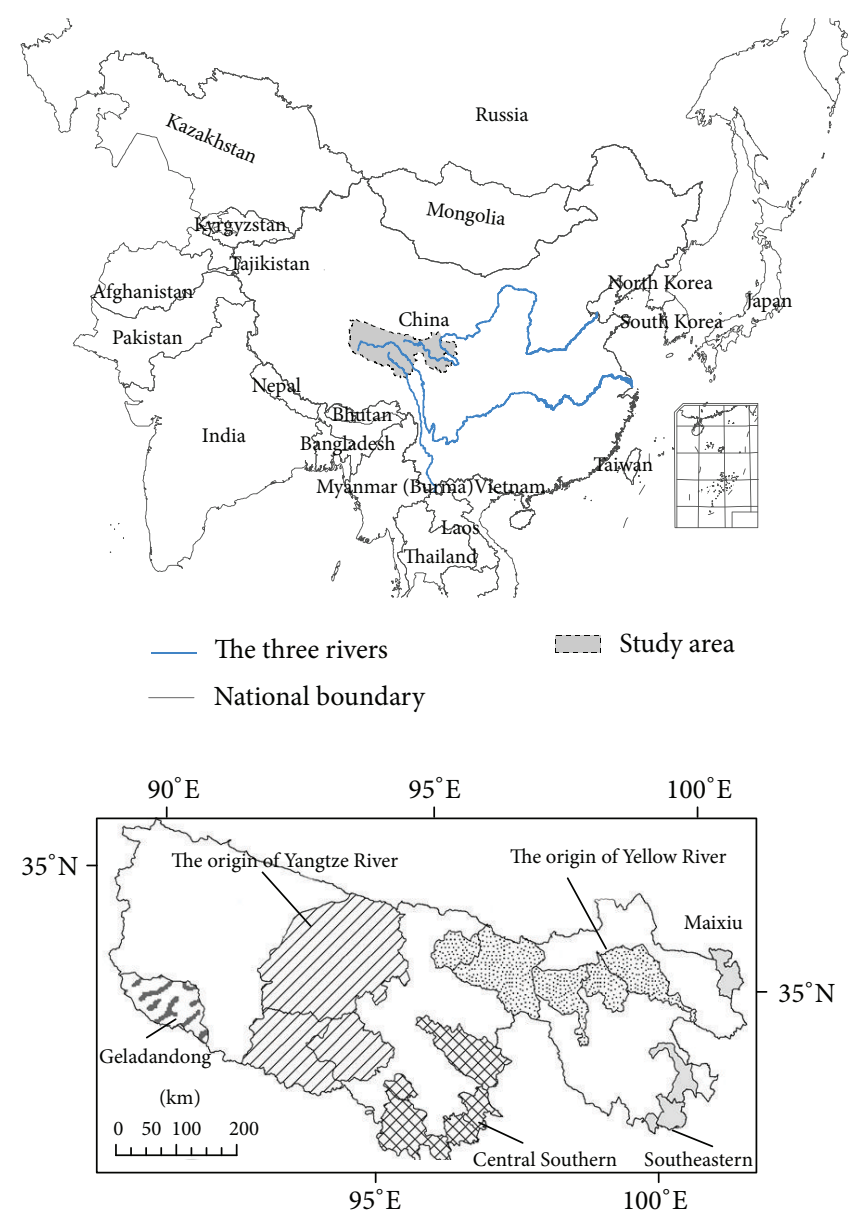

FIGURE 1: Distribution map showing the location of the TRSR.

For each meteorological station, we estimated annual potential evapotranspiration and moisture index using ground meteorological measurement and DEM as input data, applying improved Penman-Monteith and Thornthwaite moisture index to fusion processes and then to estimated water balance of this region for each year. The improved Penman-Monteith recommended by FAO in 1998 presented the PET and Thornthwaite moisture index as follows:

$$
\begin{gathered}
I_{m}=100\left(\frac{P}{E T_{0}}-1\right) \\
E T_{0}=\frac{0.408 \Delta\left(R_{n}-G\right)+\gamma(900 /(T+273)) U_{2}\left(e_{s}-e_{a}\right)}{\Delta+\gamma\left(1+0.34 U_{2}\right)} .
\end{gathered}
$$

In (1), $E T_{0}$ is the potential evapotranspiration $\left(\mathrm{mm} \mathrm{day}^{-1}\right)$, $R_{n}$ is canopy net radiation $\left(\mathrm{MJ} \mathrm{m}^{-2}\right.$ day $\left.^{-1}\right), G$ is soil heat fluxes $\left(\mathrm{MJ} \mathrm{m}^{-2}\right.$ day $^{-1}$ ), $T$ is the air temperature at $2 \mathrm{~m}$ height $\left({ }^{\circ} \mathrm{C}\right), U_{2}$ is the wind velocity at $2 \mathrm{~m}$ height $\left(\mathrm{m} \mathrm{s}^{-1}\right), e_{s}$ and $e_{a}$ are saturation vapor pressure and actual water vapor pressure, respectively $(\mathrm{kPa}), \Delta$ is curve slope of saturation vapor pressure $\left(\mathrm{kPa}^{\circ} \mathrm{C}^{-1}\right)$, and $\gamma$ is constant of psychrometer $\left(\mathrm{kPa}^{\circ} \mathrm{C}^{-1}\right)$.
2.5. Carbon Density Change. The conversion of grassland to arable land causes significant emissions of carbon to the atmosphere. For restoration and improved management of grasslands, Table 1 gives some local estimates of mitigation potential per unit area, which was meta-analyzed from other published references [19-25].

\section{Results}

3.1. Climate Change in Three River's Source Region during 1990-2012. In the periods of 1975-2012, the average annual temperature of meteorological stations in the TRSR was $-0.34^{\circ} \mathrm{C}$; the average annual temperature change rate was approximately $0.48^{\circ} \mathrm{C} / 10$ a (Figure 2). During $1990-2004$, the average annual temperature was $-0.14^{\circ} \mathrm{C}$, with the change rate of about $1.38^{\circ} \mathrm{C} / 10 \mathrm{a}$. During $2004-2012$, the annual average temperature was $0.48^{\circ} \mathrm{C}$, with the change rate of about $0.19^{\circ} \mathrm{C} / 10 \mathrm{a}$. Comparing it before and after 2004, the average temperature increased by $0.62^{\circ} \mathrm{C}$, but the warming rate is significantly reduced. In the source region of the Yangtze River, the average annual temperature of six meteorological stations from 1975 to 2012 was $-1.37^{\circ} \mathrm{C}$, and it increased by $0.72^{\circ} \mathrm{C}$ comparing the period of 2004-2012 with $1990-$ 2004. In the source region of the Yellow River, the average 
TABLE 1: Carbon density change summarized by restored or degraded grasslands.

\begin{tabular}{lccc}
\hline Types & & Carbon density $\left(\mathrm{gC} / \mathrm{m}^{2} /\right.$ year $)$ & BGB \\
& AGB & 990.108 & 20035.5 \\
Typical grassland & 159.219 & 836.748 & 16760.0 \\
Slight grassland degradation & 84.533 & 730.600 & 16145.0 \\
Middle grassland degradation & 79.398 & 201.672 & 14360.0 \\
Obvious grassland degradation & 36.302 & 50.056 & 12946.0 \\
Severe grassland degradation & 25.916 & & $\mathrm{~cm}$ \\
\hline
\end{tabular}

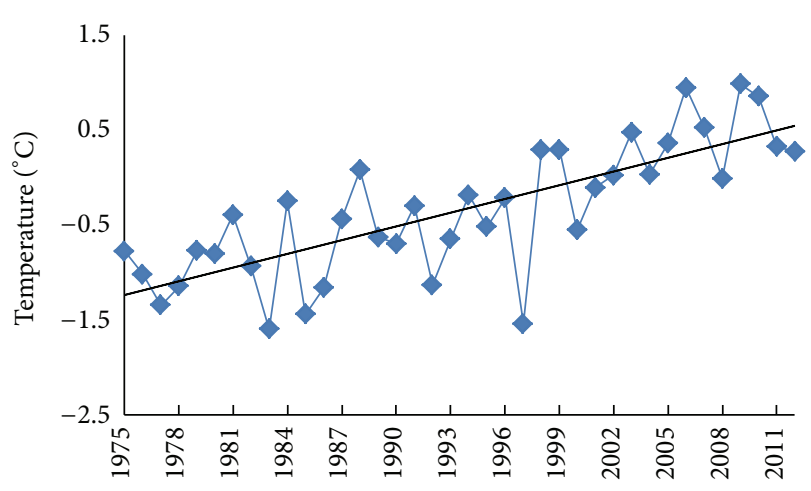

(a)

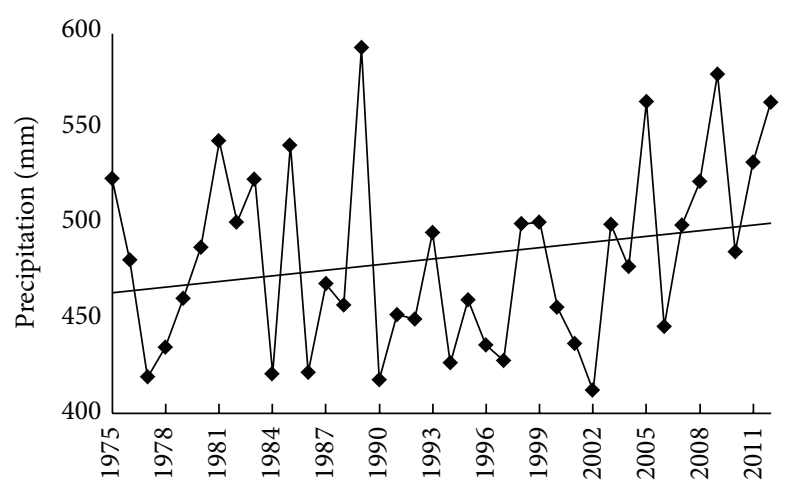

(b)

FIGURE 2: The trends of annual average temperature and annual precipitation in 1975-2012.

annual temperature of four meteorological stations from 1975 to 2012 was $-0.34^{\circ} \mathrm{C}$, and it increased by $0.41^{\circ} \mathrm{C}$ comparing the period of 2004-2012 with 1990-2004. In the source region of the Lancang River, the average annual temperature of two meteorological stations from 1975 to 2012 was $2.73^{\circ} \mathrm{C}$, and it increased by $0.72^{\circ} \mathrm{C}$ comparing the period of $2004-$ 2012 with 1990-2004. Before 2004 (Figure 3), the temperature change rates in central and southwestern of TRSR were higher than other regions, and they decreased gradually from south to north. The average altitude of average annual temperature greater than $0^{\circ} \mathrm{C}$ was $3646 \mathrm{~m}$. After 2004, the temperature change in central TRSR was more significant, and the trend was slightly lower in the Northern region. The average altitude of average annual temperature greater than $0^{\circ} \mathrm{C}$ was $3968 \mathrm{~m}$, reflecting the warming process resulting from the rises of altitude line of average annual temperature greater than $0^{\circ} \mathrm{C}$.

During 1975-2012, the average annual precipitation of meteorological stations in the TRSR was $481.83 \mathrm{~mm}$, and variation trend was $9.9 \mathrm{~mm} / 10 \mathrm{a}$ (Figure 2). During 19902004, the average annual precipitation was $463.56 \mathrm{~mm}$, with trend of about $7.02 \mathrm{~mm} / 10 \mathrm{a}$. During 2004-2012, the average annual precipitation was $518.66 \mathrm{~mm}$, with the trend of about $68.44 \mathrm{~mm} / 10 \mathrm{a}$. Comparing it before and after 2004, annual precipitation increased by $55.10 \mathrm{~mm}$, and increasing trend is more pronounced. In the source region of the Yangtze River, the average annual precipitation of six meteorological stations from 1975 to 2012 was $461.66 \mathrm{~mm}$, and it increased by $64.17 \mathrm{~mm}$ comparing the period of 2004-2012 with 19902004. In the source region of the Yellow River, the average annual precipitation of four meteorological stations from
1975 to 2012 was $481.78 \mathrm{~mm}$, and it increased by $57.63 \mathrm{~mm}$ comparing the period of 2004-2012 with 1990-2004. In the source region of the Lancang River, the average annual precipitation of two meteorological stations from 1975 to 2012 was $542.48 \mathrm{~mm}$, and it increased by $22.84 \mathrm{~mm}$ comparing the period of 2004-2012 with 1990-2004. The western and southwestern region of TRSR showed larger increased precipitation; however, the change rate of annual precipitation was increased less in eastern and gradually in central TRSR (Figure 3).

During 1975-2012, the average annual humidity index in TRSR was -57 , with ranges between -86 and -12 (Figure 3 ). Comparing it during 1990-2004 with 2004-2012, average annual humidity index was increased by about 3.75, from -57 to -53 . Before 2004 , humidity index presented a weak decreasing trend, especially in southeastern part. Since 2004, it began an upward trend especially in central regions, but with more significant downward trend in the southern. In the periods of 1975-2012, the average annual humidity index decreased from the southeast to the northwest region. High values of humidity index were mainly distributed in area with relatively lower temperature and potential evapotranspiration and higher rainfall, such as higher mountains in the southeastern and southern part. Low values were mainly distributed in the area of lower temperature, potential evapotranspiration, and annual precipitation, such as alpine steppe and desert areas in northwestern part.

3.2. Grassland Degradation and Restoration over the Past 40 Years. The spatial distribution pattern of degraded grassland in three rivers source region has been basically formed 


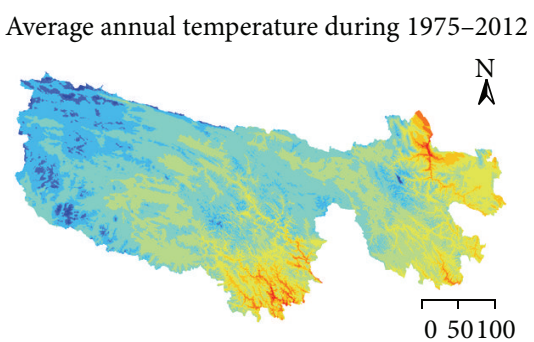

$(\mathrm{km})$
Trend of temperature during 1975-2012

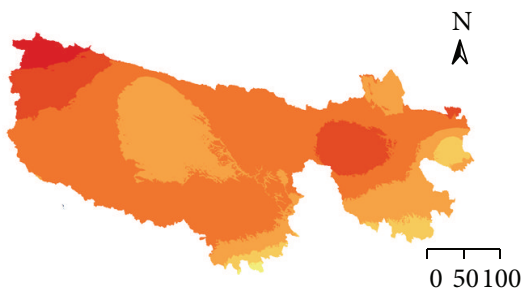

$(\mathrm{km})$

Average annual precipitation during 1975-2012

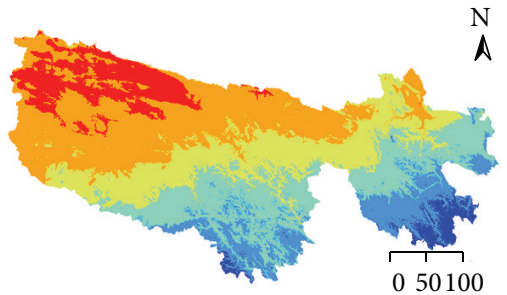

$(\mathrm{km})$

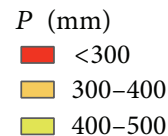

(b)
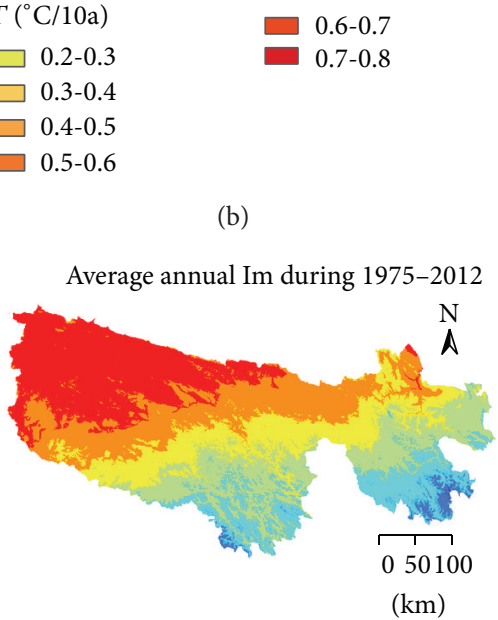

$(\mathrm{km})$

$T\left({ }^{\circ} \mathrm{C} / 10 \mathrm{a}\right)$
$\square 0.2-0.3$
$\square 0.3-0.4$
$\square 0.4-0.5$
$\square 0.5-0.6$

Trend of precipitation during 1975-2012
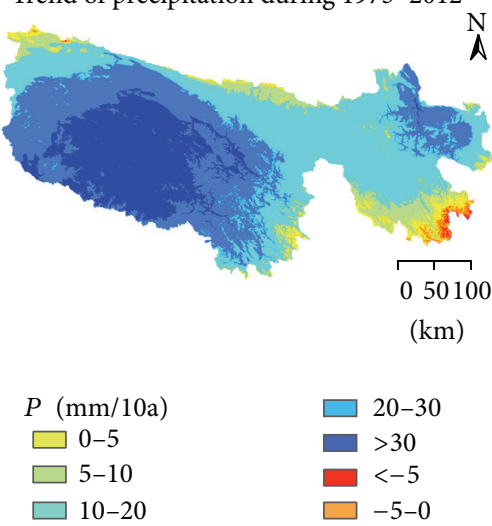

(d)
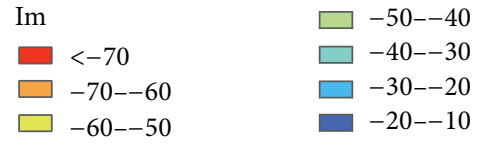

(e)
$A$

Figure 3: The map of temperature, precipitation, and humidity index during 1975-2012.

in 1970s, and the grassland degradation processes continued to occur from the late 1970s to 2004 (Figure 4). During 1970s 1990, area of grassland degradation was $76444.9 \mathrm{~km}^{2}$, accounting for $32.83 \%$ of the region's grassland area. From 1990 to 2004, area of grassland degradation was $84102.66 \mathrm{~km}^{2}$, accounting for $36.12 \%$ of the region's grasslands. Comparing the area of grassland degradation before and after 2004 , it was increased by $3.87 \%$. From the degree of degradation (Table 2), the grassland degradation in TRSR showed mainly the light and moderate degradation, with severe degradation occurring only in local area. The slightly degraded grassland accounts for $22.88 \%$ of the region's total grassland area in 1970s 1990, and it rose to $23.93 \%$ from 1990 to 2004 , an increase of $1.05 \%$. In the late 1970 s to 1990 , the moderately degraded grassland accounted for $9.5 \%$ of the total grassland, while it rose to $11.74 \%$ from 1990 to 2004, an increase of $2.24 \%$.

From 2004 to 2012, the original patches of grassland degradation in the TRSR showed varying degrees of restoration, and the grass situation even improved in some areas. The area of nonchange degradation was $60213.5 \mathrm{~km}^{2}$, accounting for $68.52 \%$ of the total degraded grassland. Improved grassland was $22927.5 \mathrm{~km}^{2}$, accounting for $31.02 \%$ of the total degraded grassland. Among the improved grassland, light improvement of degraded grassland accounted for $24.85 \%$ of the total degraded grassland, and obvious improvement accounted for $6.17 \%$. The area of intensified degraded grassland was $297.5 \mathrm{~km}^{2}$, accounting for $0.34 \%$ of the total degraded grassland. The new occurrence of degraded grassland was $105.9 \mathrm{~km}^{2}$. Compared with the early 1990 s to 2004 , the light, moderate, and severe degraded grassland areas were significantly reduced, especially the moderately degraded grassland which decreased by $5.35 \%$, while the light and severe grassland declined by only $0.33 \%$ and $0.09 \%$.

The area of improved grassland in the source region of Yellow River, Yangtze River, and Lancang River were $9145.91 \mathrm{~km}^{2}, 10750.49 \mathrm{~km}^{2}$, and $1409.68 \mathrm{~km}^{2}$, accounting for $42.93 \%, 50.46 \%$, and $6.62 \%$ of the total improved grassland in TRSR, respectively (Table 3 ). The grassland degradation in the source region of Yangtze River was more obvious than the Yellow River and the Lancang River, in which intensified grassland degradation was $206.75 \mathrm{~km}^{2}$, accounting for $69.85 \%$ of intensified degradation in TRSR. And the new occurring degradation in the Yangtze River was $86.34 \mathrm{~km}^{2}$, accounting for $86.28 \%$ of the total new occurring in TRSR. 
The map of grassland degradation during 1990-2004

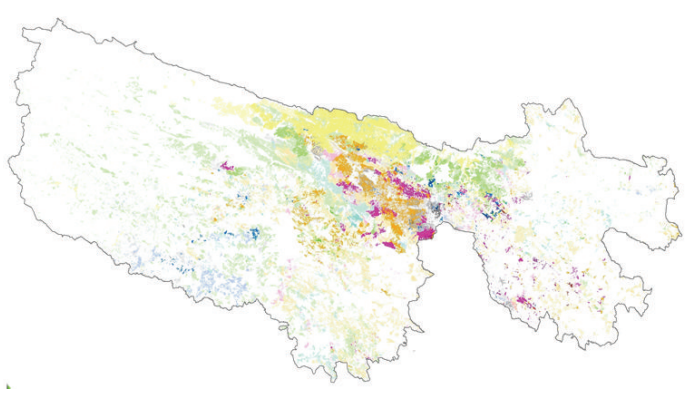

The degradation and restoration of grassland ecosystem during 2004-2012

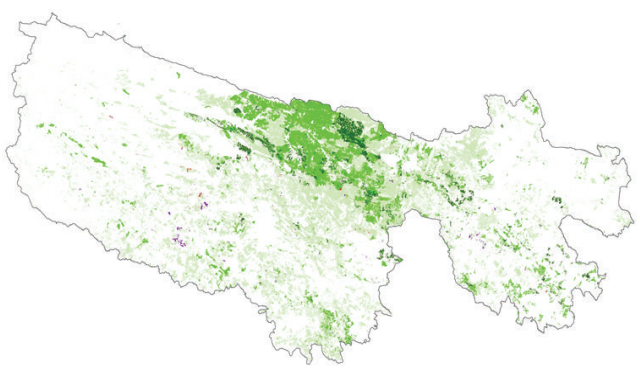

Slight fragmentation Moderate fragmentation Serious fragmentation Coverage slight degree Coverage moderate degree Coverage serious degree Meadow slight drying Meadow moderate drying Meadow serious drying Marsh slight drying Marsh moderate drying Marsh serious drying

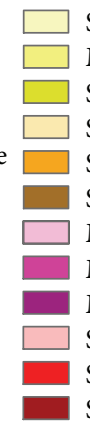

Slight sandification

Moderate sandification

Serious sandification

Slight fragmentation, coverage slight degree Slight fragmentation, coverage moderate degree Slight fragmentation, coverage serious degree Moderate fragmentation, coverage slight degree Moderate fragmentation, coverage moderate degree Moderate fragmentation, coverage serious degree Serious fragmentation, coverage slight degree Serious fragmentation, coverage moderate degree Serious fragmentation, coverage serious degree

(a)

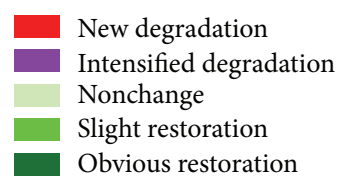

(b)

FIGURE 4: The map of grassland degradation during 1990-2004 and 2004-2012 in TRSR.

TABLE 2: The area of grassland degradation and its proportion accounted in total grassland in TRSR.

\begin{tabular}{|c|c|c|c|c|c|c|}
\hline \multirow{2}{*}{ Type } & \multicolumn{2}{|c|}{$1970 s \sim 1990$} & \multicolumn{2}{|c|}{ 1990 2004 } & \multicolumn{2}{|c|}{$2004 \sim 2012$} \\
\hline & Area $\left(\mathrm{km}^{2}\right)$ & Proportion (\%) & Area $\left(\mathrm{km}^{2}\right)$ & Proportion (\%) & Area $\left(\mathrm{km}^{2}\right)$ & Proportion (\%) \\
\hline Light degradation & 53283.17 & 22.88 & 55724.05 & 23.93 & 54948.62 & 23.60 \\
\hline Moderate degradation & 22122.16 & 9.50 & 27347.79 & 11.74 & 14874.46 & 6.39 \\
\hline Severe degradation & 1039.57 & 0.45 & 1030.82 & 0.44 & 809.95 & 0.35 \\
\hline Restoration & 674.65 & 0.29 & 61.59 & 0.03 & 273.49 & \\
\hline
\end{tabular}

TABLE 3: The statistics of grassland degradation/restoration for TRSR (unit: $\mathrm{km}^{2}$ ).

\begin{tabular}{|c|c|c|c|c|}
\hline \multirow{2}{*}{ Type } & \multicolumn{3}{|c|}{ The source region of } & \multirow{2}{*}{ Total } \\
\hline & Yellow River & Yangtze River & Lancang River & \\
\hline New occurring degradation & 19.56 & 86.34 & 0 & 105.9 \\
\hline Intensified degradation & 79.16 & 206.75 & 11.59 & 297.5 \\
\hline Non-change & 20469.42 & 30760.46 & 8983.62 & 60213.5 \\
\hline Slight restoration & 6610.18 & 8763.27 & 1304.94 & 16678.39 \\
\hline Substantial restoration & 2535.73 & 1987.22 & 104.74 & 4627.69 \\
\hline Marsh restoration & 728.13 & 819.33 & 73.91 & 1621.37 \\
\hline
\end{tabular}

3.3. Grassland Vegetation Coverage Change over the Past 40 Years. Comparing it before and after 2004, the grassland vegetation coverage showed significant increase in TRSR. The area of slightly improved vegetation coverage accounted for $67.62 \%$ of total grassland (Table 4 ) and obvious improvement accounted for $4.58 \%$, while the decreased vegetation coverage only accounted for $3.84 \%$. From the spatial distribution after 2004, obvious improved grassland vegetation coverage was mainly concentrated in the North Xinghai County and Madoi County (Figure 5), which showed increasing rate of more than $10 \%$ in vegetation coverage and could be contributed to ecological protection and construction projects since 2005.

Although the vegetation coverage of TRSR has improved significantly, but comparing it with healthy grassland vegetation coverage, the gap is large (Figure 2, Table 5). Comparing current grassland vegetation coverage with healthy vegetation 


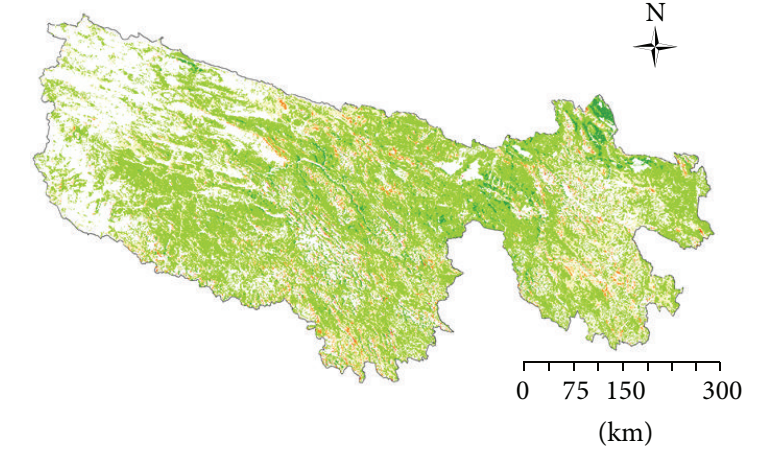

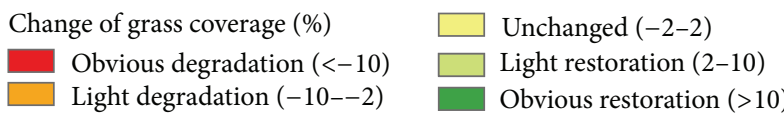

(a)

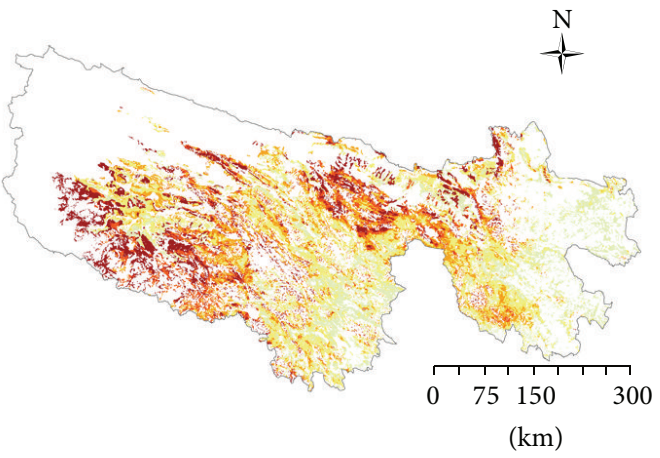

Gap to healthy grassland (\%) $\square \begin{aligned} & 20-30 \\ & 30-40 \\ & \square 0-10\end{aligned}$
$\square=40$

(b)

FIGURE 5: The change of vegetation coverage before and after 2004 (a) and the gap between current vegetation coverage and healthy grassland (b).

TABLE 4: The change of vegetation coverage before and after 2004.

\begin{tabular}{lcc}
\hline $\begin{array}{l}\text { Classification of vegetation } \\
\text { coverage }\end{array}$ & \multicolumn{2}{c}{$\begin{array}{c}\text { The change of vegetation coverage } \\
\text { before and after } 2004\end{array}$} \\
& Area $\left(\mathrm{km}^{2}\right)$ & Proportion (\%) \\
\hline $\begin{array}{l}\text { Obvious degradation } \\
(<-10 \%)\end{array}$ & 338 & 0.12 \\
$\begin{array}{l}\text { Slight degradation } \\
(-10 \%--2 \%)\end{array}$ & 10468 & 3.72 \\
$\begin{array}{l}\text { Nonchange } \\
(-2 \%-2 \%)\end{array}$ & 67355 & 23.96 \\
$\begin{array}{l}\text { Slight restoration } \\
(2 \%-10 \%)\end{array}$ & 190061 & 67.62 \\
$\begin{array}{l}\text { Substantial restoration } \\
(>10 \%)\end{array}$ & 12868 & 4.58 \\
\hline
\end{tabular}

cover with the same grass type, $46.11 \%$ of the area still needs to further restore vegetation cover, mainly distributed in the source region of the Yellow River and the Yangtze River.

\subsection{Climate Change Mitigation Potential of Grassland Restora-} tion. From 1990 to 2004, the grassland degradation caused significant emissions of carbon to the atmosphere, which is estimated to cause an average loss of $6.466 \mathrm{MtC}, 16.423 \mathrm{MtC}$, and $294.464 \mathrm{MtC}$ from above- and belowground biomass and soil carbon pools, the main carbon pool in grassland ecosystem in TRSR (Table 6), in which slight degradation results in large portion of carbon losses and accounts for $64.37 \%, 52.04 \%$, and $61.99 \%$ of the total loss from aboveand belowground biomass and soil carbon pools, respectively. However, grassland restoration in the periods only sequestered $0.346 \mathrm{MtC}$.

From 2004 to 2012, the grassland degradation caused relatively lower emissions of carbon to the atmosphere compared to that before 2004, which is estimated to cause losses of 5.363 MtC, 12.78 MtC, and 241.087 MtC from above-
TABLE 5: The gap between current vegetation coverage and healthy grassland.

\begin{tabular}{lcc}
\hline $\begin{array}{l}\text { Classification of the } \\
\text { gap }\end{array}$ & Area $\left(\mathrm{km}^{2}\right)$ & $\begin{array}{c}\text { Proportion account in total } \\
\text { grassland of TRSR (\%) }\end{array}$ \\
\hline $0 \sim 10 \%$ & 31595 & 11.24 \\
$10 \sim 20 \%$ & 37805 & 13.45 \\
$20 \sim 30 \%$ & 25914 & 9.22 \\
$30 \sim 40 \%$ & 16904 & 6.01 \\
$>40 \%$ & 17355 & 6.17 \\
\hline Total & 129573 & 46.11 \\
\hline
\end{tabular}

and belowground biomass and soil carbon pools in TRSR (Table 6), in which slight degradation results in carbon losses accounting for $76.52 \%, 65.94 \%$, and $74.66 \%$ of the total loss from above- and belowground biomass and soil carbon pools, respectively. In addition, grassland restoration in the periods sequestered $1.537 \mathrm{MtC}, 4.4$ times more than that before 2004 .

Various methods of grassland restoration and/or improved management can sequester carbon in soils and in below- and aboveground biomass. For restored and improved grasslands, we give some estimates of mitigation potential per unit area under the scenario of grassland restoring to healthy status. The estimates presented are subject to a range of assumptions and uncertainties. The restoration of degraded grasslands to their healthy status has been estimated to be a technical mitigation potential of $515.074 \mathrm{MtC}\left(167.53 \mathrm{gC} / \mathrm{m}^{2} /\right.$ year $), 44.568 \mathrm{MtC}$ (344.01 gC/ $/ \mathrm{m}^{2} /$ year), and $21.705 \mathrm{MtC}\left(3975.65 \mathrm{gC} / \mathrm{m}^{2} /\right.$ year $)$ in soils, and in below- and aboveground biomass.

Figure 6 shows the overlay of grasslands with areas in which there estimated to be a gap between current carbon stocks and their biophysical potential. It is an indicator of potential to sequester additional carbon. The map indicates, for example, areas in the source region of Yellow River and 
TABLE 6: Carbon sequestration summarized by types of restored or degraded grasslands.

\begin{tabular}{lcccccc}
\hline \multirow{2}{*}{ Types } & \multicolumn{3}{c}{$1990-2004(\mathrm{MtC})$} & \multicolumn{3}{c}{$2004-2012(\mathrm{MtC})$} \\
& AGB & BGB & SOC in 0 40 cm & AGB & BGB & SOC in 0 40 cm \\
\hline Slight degradation & -4.162 & -8.546 & -182.524 & -4.104 & -8.427 & -179.984 \\
Middle degradation & -2.183 & -7.097 & -106.397 & -1.187 & -3.860 & -57.869 \\
Substantial degradation & -0.127 & -0.813 & -5.850 & -0.100 & -0.639 & -4.597 \\
Restoration & 0.006 & 0.033 & 0.307 & 0.028 & 0.146 & -1.363 \\
\hline Total & -6.466 & -16.423 & -294.464 & -5.363 & -12.78 & -241.087 \\
\hline
\end{tabular}

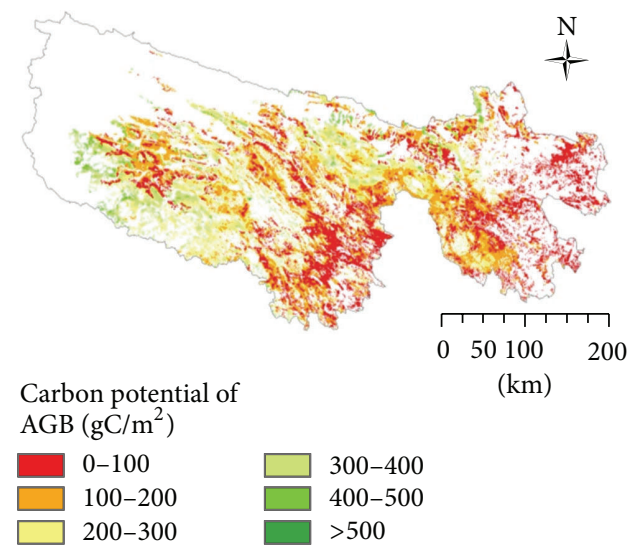

(a)

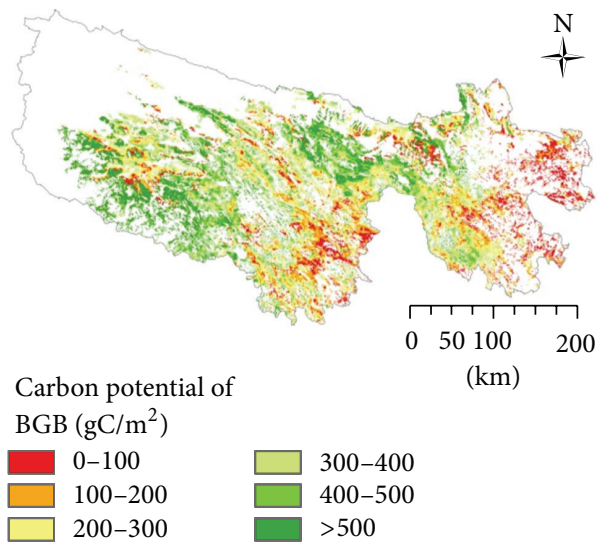

(b)

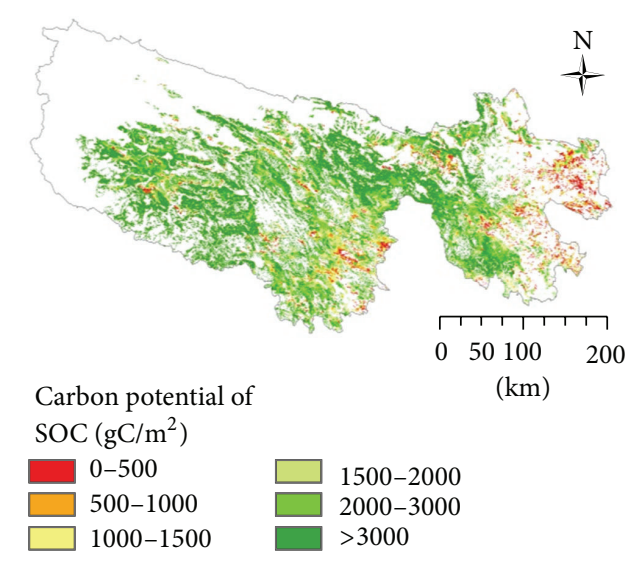

(c)

FIGURE 6: The carbon potential of AGB, BGB, and SOC in depth of $40 \mathrm{~cm}$ by grassland restoration to healthy status.

Yangtze River with relatively high carbon gaps. In particular the source region of Yellow River is a region with a significant carbon sequestration potential. In this area, the government is already supporting policies such as restoring grassland from grazing, area enclosure programmes, and intensive feed production systems to reduce degradation pressure which restore carbon and close the carbon gap.

\section{Discussion and Conclusions}

Climate change could impact ecosystems positively in wetter regions and negatively in drier ones. Annual average temperature in TRSR during $2004-2012$ increased by $1.29^{\circ} \mathrm{C}$ compared with that in 1975-2004. The increasing rate of annual temperature in TRSR was $0.49^{\circ} \mathrm{C} 10 \mathrm{yr}^{-1}$ and $0.58^{\circ} \mathrm{C}$ $10 \mathrm{yr}^{-1}$ during 1975-2004 and 1975-2012, respectively, which illustrates rapid warming over recent years. Warm and wet climatic conditions promote vegetation growth and increase forage yield in TRSR. Average annual precipitation in 20052012 increased by $61 \mathrm{~mm}$ compared with that during 19752004. The change rate of annual precipitation was $-4.6 \mathrm{~mm}$

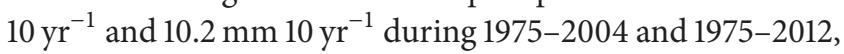
respectively, which shows a clear rise in recent years.

Global environmental change, including climate change, spread of invasive species, and increased pollution, could strongly affect the ability to restore ecosystems. One response 
would be to determine how restoration might be used to increase resilience of biodiversity and ecosystem services to global change [26]. Recent progress in understanding the resilience of coupled social-ecological systems [27] provides a basis for understanding how this might be achieved in practice. Further research should identify thresholds beyond which ecological recovery might be slow or impossible and should suggest how changes in human behavior can be achieved to address the causes of ecological degradation [3].

The impacts of climate changes on biological systems are manifested as shifts in phenology and physiology, the composition of and interactions within communities, the range and distribution of species, morphology, net primary productivity, and the structure and dynamics of ecosystems [28]. Ecological responses to recent climate change are already clearly visible by altering their phenology and geographical distributions [29] and changes even greater for the 21st century [30]. Climate change also poses a grave threat to biodiversity by exacerbating existing threats from landuse change, fragmentation, and environmental degradation [31]. Assessments of climate change impacts on biodiversity have often used bioclimatic envelope models [32], to forecast continental-wide impacts of climate change on large numbers of species [33]. However, the complexity of ecological interactions renders it difficult to extrapolate from studies of individuals and populations to the community or ecosystem level. As a result of the widespread loss and fragmentation of habitats, many areas may become climatically unsuitable for many species [28]. It has been brought into a sharper focus by the increasing threats to protected areas through climate change and debate about whether protected areas remain relevant in periods of rapid biophysical and social change [34].

Studies have occasionally examined impacts of climate change on conservation areas. Ecosystem projected to be primarily affected by climate change may require adapted measures, compared to that negatively affected by land-use change that could persist through protection of their remaining natural habitat [34]. The characteristics of protected areas, where planning has to be done decades in advance [35], need to be reviewed under climate change to minimize the effects of climate change as well as for climate refuges of biodiversity [36]. Enhanced conservation efforts will play a critical role in efforts to reduce the impacts of climate change on biodiversity and ecosystem services [37]. It is becoming evident that in addition to providing sustainable management of habitats and ecosystems, effective conservation strategies need to mitigate impacts of climate change [32].

Although the use of ecosystem service markets to support restoration has been questioned in terms of the ability of restoration to deliver specified services [38], it is also appropriate to ask whether payment for ecosystem services (PES) can help achieve restoration goals, such as the convention on biological diversity (CBD) targets. PES might focus restoration activities on a limited set of services, such as carbon sequestration [39], whereas other services or biodiversity is neglected. This could be a particular problem when international markets are brought into play, which might override local concerns. The desired link between reversing environmental degradation and alleviating poverty might also be undermined by an excessive reliance on market forces, as poor people do not always benefit from PES [10]. For restoration to contribute both to sustainable development and the alleviation of poverty, it is essential that such financial flows compensate landholders adequately for any costs of restoration and provide an effective incentive to initiate restoration actions. Identifying how this might be achieved, based on understanding of the potential distribution of benefits among different stakeholders and the conflicts that could arise, represents a major challenge to future restoration research and practice [3].

Various methods of improved grassland management can sequester carbon $[14,15]$. However, the global analysis in particular for some regions has a high level of uncertainty. Primary among these uncertainties are the costs at which carbon sequestration is economically viable. Several studies suggest that compared to other mitigation options, grassland mitigation is cost-competitive [16, 17], but further work is needed to validate this. There are several types of cost to consider regarding any change in management practice, including initial investment costs, annual operating costs, and opportunity costs of income foregone by undertaking the activities needed for avoiding conversion of or improving management of grasslands [40]. While degraded grasslands may have significant potential for carbon sequestration, initial costs of restoration and the delayed return before grasslands recover their productivity imply that costs will not in all cases be low [18].

\section{Conflict of Interests}

The authors declare that there is no conflict of interests regarding the publication of this paper.

\section{Acknowledgments}

This work was financially supported by the CDM Program (1214115). The authors thank anonymous reviewers for their helpful comments on this paper.

\section{References}

[1] K. M. Havstad, D. P. C. Peters, R. Skaggs et al., "Ecological services to and from rangelands of the United States," Ecological Economics, vol. 64, no. 2, pp. 261-268, 2007.

[2] S. H. M. Butchart, M. Walpole, B. Collen et al., "Global biodiversity: indicators of recent declines," Science, vol. 328, no. 5982, pp. 1164-1168, 2010.

[3] J. M. Bullock, J. Aronson, A. C. Newton, R. F. Pywell, and J. M. Rey-Benayas, "Restoration of ecosystem services and biodiversity: conflicts and opportunities," Trends in Ecology and Evolution, vol. 26, no. 10, pp. 541-549, 2011.

[4] W. H. Schlesinger, J. F. Reynolds, G. L. Cunningham et al., "Biological feedbacks in global desertification," Science, vol. 247, no. 4946, pp. 1043-1048, 1990. 
[5] A. Wilkes, K. Solymosi, and T. Tennigkeit, "Options for support to grassland restoration in the context of climate change mitigation," Tech. Rep., UNIQUE Forestry and Land Use, Freiburg, Germany, 2012.

[6] W. Jordan, M. Gilpin, and J. Aber, Eds., Restoration Ecology: A Synthetic Approach to Ecological Research, Cambridge University Press, Cambridge, UK, 1987.

[7] G. C. Daily and P. A. Matson, "Ecosystem services: from theory to implementation," Proceedings of the National Academy of Sciences of the United States of America, vol. 105, no. 28, pp. 9455-9456, 2008.

[8] J. M. Rey-Benayas, A. C. Newton, A. Diaz, and J. M. Bullock, "Enhancement of biodiversity and ecosystem services by ecological restoration: a meta-analysis," Science, vol. 325, no. 5944, pp. 1121-1124, 2009.

[9] R. Naidoo, A. Balmford, R. Costanza et al., "Global mapping of ecosystem services and conservation priorities," Proceedings of the National Academy of Sciences of the United States of America, vol. 105, no. 28, pp. 9495-9500, 2008.

[10] L. M. Martin, K. A. Moloney, and B. J. Wilsey, "An assessment of grassland restoration success using species diversity components," Journal of Applied Ecology, vol. 42, no. 2, pp. 327-336, 2005.

[11] R. F. Pywell, J. M. Bullock, A. Hopkins et al., "Restoration of species-rich grassland on arable land: assessing the limiting processes using a multi-site experiment," Journal of Applied Ecology, vol. 39, no. 2, pp. 294-309, 2002.

[12] G. Cao and R. Long, "The Bottleneck and its resolutions to the natural recovery of black soil type degraded grassland in the three river Source Region," Acta Agrestia Sinica, vol. 17, no. 1, pp. 4-9, 2009.

[13] T. J. Stohlgren, T. N. Chase, R. A. Pielke Sr., T. G. F. Kittel, and J. S. Baron, "Evidence that local land use practices influence regional climate, vegetation, and stream flow patterns in adjacent natural areas," Global Change Biology, vol. 4, no. 5, pp. 495$504,1998$.

[14] R. T. Conant, K. Paustian, and E. T. Elliott, "Grassland management and conversion into grassland: effects on soil carbon," Ecological Applications, vol. 11, no. 2, pp. 343-355, 2001.

[15] B. Kumar and P. Nair, Carbon Sequestration Potential of Agroforestry Systems: Opportunities and Challenges, Springer, New York, NY, USA, 2011.

[16] P. Smith, D. Martino, Z. Cai et al., "Greenhouse gas mitigation in agriculture," Philosophical Transactions of the Royal Society B: Biological Sciences, vol. 363, no. 1492, pp. 789-813, 2008.

[17] McKinsey \& Co, China's Green Revolution: Prioritizing technologies to Achieve Energy and Environmental Sustainability, McKinsey \& Co, London, UK, 2009.

[18] L. Lipper, C. Dutilly-Diane, and N. McCarthy, "Supplying carbon sequestration from West African rangelands: opportunities and barriers," Rangeland Ecology and Management, vol. 63, no. 1, pp. 155-166, 2010.

[19] H. Y. Li, H. C. Peng, and Q. J. Wang, "Study on aboveground biomass of plant communities among the stages of regressive succession in alpine Kobresia humilis meadow," Acta Pratacultural Science, vol. 13, no. 5, pp. 26-32, 2004.

[20] H. K. Zhou, X. Q. Zhao, L. Zhou et al., "A study on correlation between vegetation degradation and soil degradation in the alpine meadow of the Qinghai-Tibetan Plateau," Acta Pratacultural Science, vol. 14, no. 3, pp. 31-40, 2005.

[21] W. Y. Wang, Q. J. Wang, G. Wang, and Z. C. Jing, "Effects of land degradation and rehabilitation on vegetation carbon and nitrogen content of alpine meadow in China," Journal of Plant Ecology, vol. 31, no. 6, pp. 1073-1078, 2007.

[22] Y. N. Zeng, Z. L. Ma, and Z. D. Feng, "Potential to sequestering carbon from atmosphere through rehabilitating desert land in the head water of the Yellow River," Journal of Mountain Science, vol. 27, no. 6, pp. 671-675, 2009.

[23] J. L. Yu, H. X. Shi, and C. Y. Zhao, "Preliminary study on range conditions of alpine Kobresia meadows under different degradation degrees," Acta Prataculturae Snica, vol. 27, no. 9, pp. 115-118, 2010.

[24] D. R. Han, G. M. Cao, X. W. Guo et al., "The potential of carbon sink in alpine meadow ecosystem on the QinghaiTibetan Plateau," Acta Ecologica Sinica, vol. 31, no. 24, pp. 74087417, 2011.

[25] Y. N. Li, S. X. Xu, L. Zhao, and F. W. Zhang, "Carbon Sequestration potential of vegetation and soil of degenerative alpine meadows in Southern Qinghai Province," Journal of Glaciology and Geocryology, vol. 34, no. 5, pp. 1157-1164, 2012.

[26] J. M. Montoya and D. Raffaelli, "Climate change, biotic interactions and ecosystem services," Philosophical Transactions of the Royal Society B: Biological Sciences, vol. 365, no. 1549, pp. 20132018, 2010.

[27] J. G. Liu, T. Dietz, S. R. Carpenter et al., "Complexity of coupled human and natural systems," Science, vol. 317, no. 5844, pp. 15131516, 2007.

[28] G. R. Walther, E. Post, P. Convey et al., "Ecological responses to recent climate change," Nature, vol. 416, no. 6879, pp. 389-395, 2002.

[29] J. Lenoir, J. C. Gégout, P. A. Marquet, P. De Ruffray, and H. Brisse, "A significant upward shift in plant species optimum elevation during the 20th century," Science, vol. 320, no. 5884, pp. 1768-1771, 2008.

[30] W. Thuiller, S. Lavergne, C. Roquet, I. Boulangeat, B. Lafourcade, and M. B. Araujo, "Consequences of climate change on the tree of life in Europe," Nature, vol. 470, no. 7335, pp. 531534, 2011.

[31] D. D. Ackerly, S. R. Loarie, W. K. Cornwell et al., "The geography of climate change: implications for conservation biogeography," Diversity and Distributions, vol. 16, no. 3, pp. 476-487, 2010.

[32] M. B. Araújo, D. Alagador, M. Cabeza, D. Nogués-Bravo, and W. Thuiller, "Climate change threatens European conservation areas," Ecology Letters, vol. 14, no. 5, pp. 484-492, 2011.

[33] S. Z. Dobrowski, J. H. Thorne, J. A. Greenberg et al., "Modeling plant ranges over 75 years of climate change in California, USA: temporal transferability and species traits," Ecological Monographs, vol. 81, no. 2, pp. 241-257, 2011.

[34] L. Hannah, G. Midgley, S. Andelman et al., "Protected area needs in a changing climate," Frontiers in Ecology and the Environment, vol. 5, no. 3, pp. 131-138, 2007.

[35] L. Hansen, J. Hoffman, C. Drews, and E. Mielbrecht, "Designing climate-smart conservation: guidance and case studies: special section," Conservation Biology, vol. 24, no. 1, pp. 63-69, 2010.

[36] C. Bellard, C. Bertelsmeier, P. Leadley, W. Thuiller, and F. Courchamp, "Impacts of climate change on the future of biodiversity, Ecology Letters, vol. 15, no. 4, pp. 365-377, 2012. 
[37] J. J. Lawler, T. H. Tear, C. Pyke et al., "Resource management in a changing and uncertain climate," Frontiers in Ecology and the Environment, vol. 8, no. 1, pp. 35-43, 2010.

[38] M. A. Palmer and S. Filoso, "Restoration of ecosystem services for environmental markets," Science, vol. 325, no. 5940, pp. 575576, 2009.

[39] F. E. Putz and K. H. Redford, "Dangers of carbon-based conservation," Global Environmental Change, vol. 19, no. 4, pp. 400401, 2009.

[40] L. Lipper, A. Wilkes, and N. McCarthy, "Crediting soil carbon sequestration in smallholder agricultural systems: what fits and what will fly?" in Monitoring, Reporting and Verification Systems for Carbon in Soils and Vegetation in African, Caribbean and Pacific Countries, D. de Brogniez, P. Mayaux, and L. Montanarella, Eds., EC JRC Scientific and Technical Reports, EC European Commission Joint Research Centre, Brussels, Belgium, 2011. 

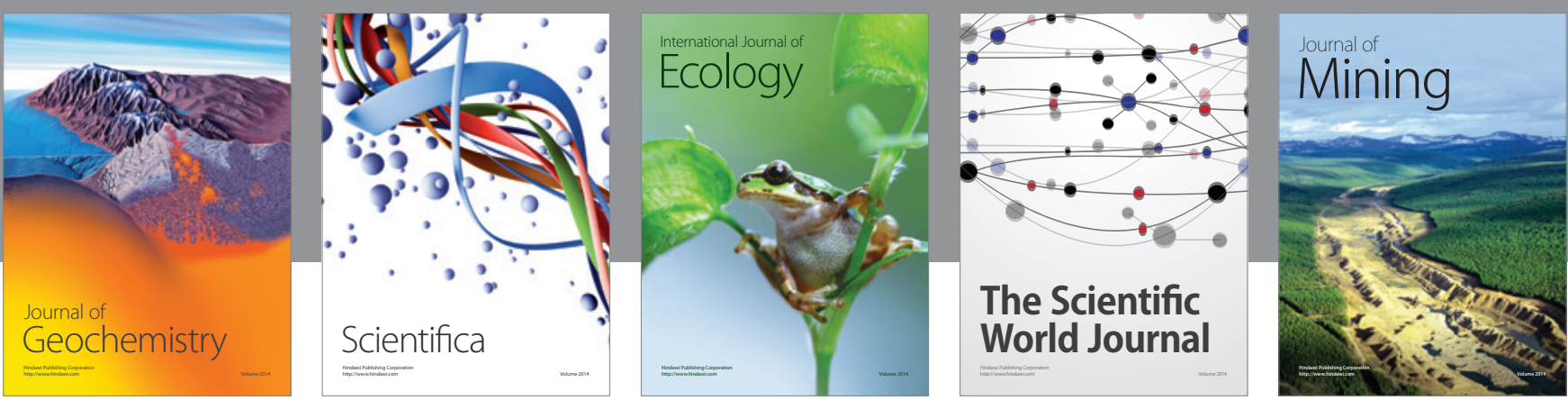

The Scientific World Journal
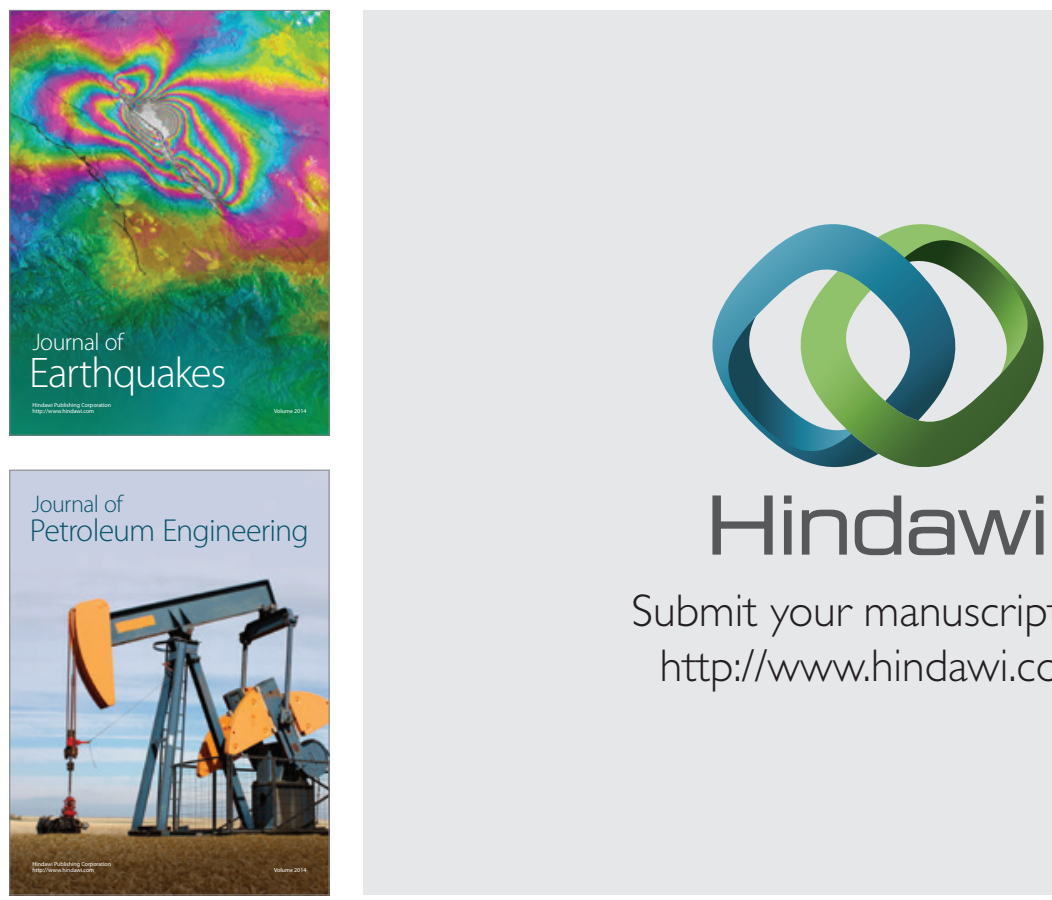

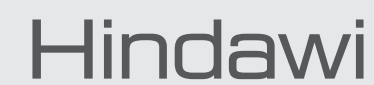

Submit your manuscripts at

http://www.hindawi.com
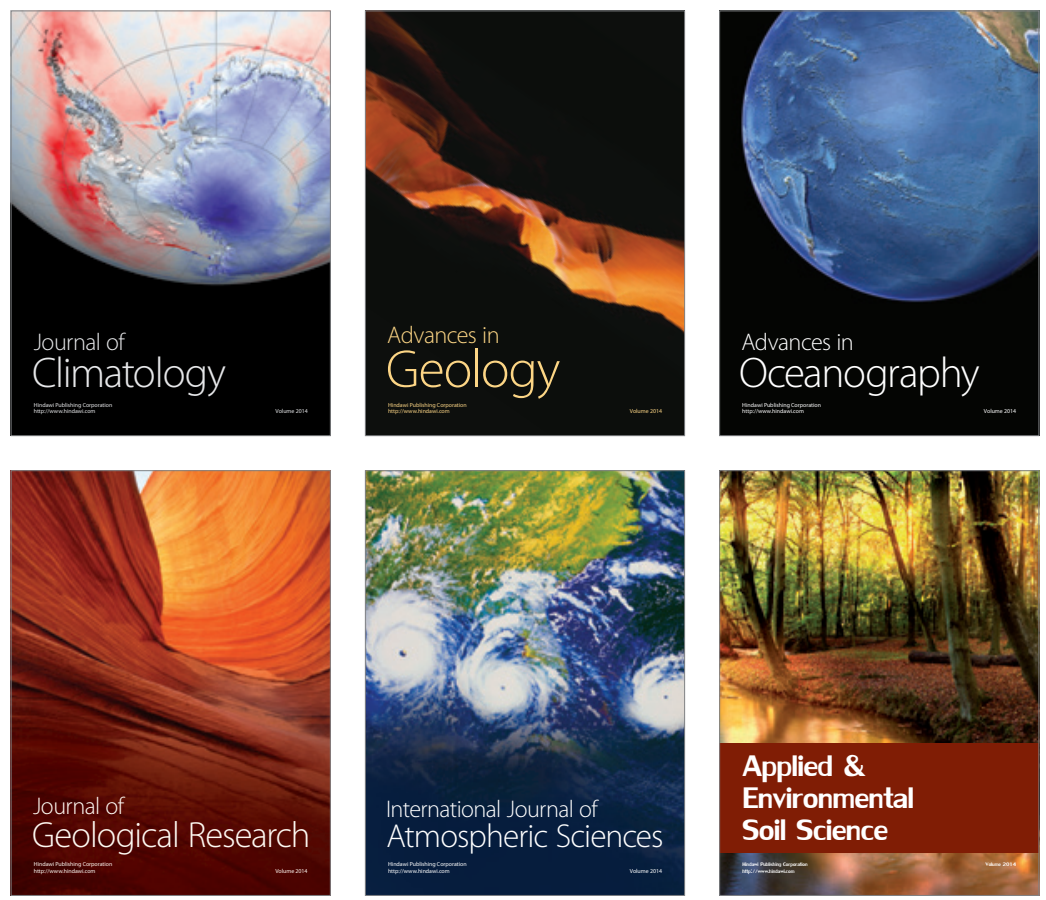
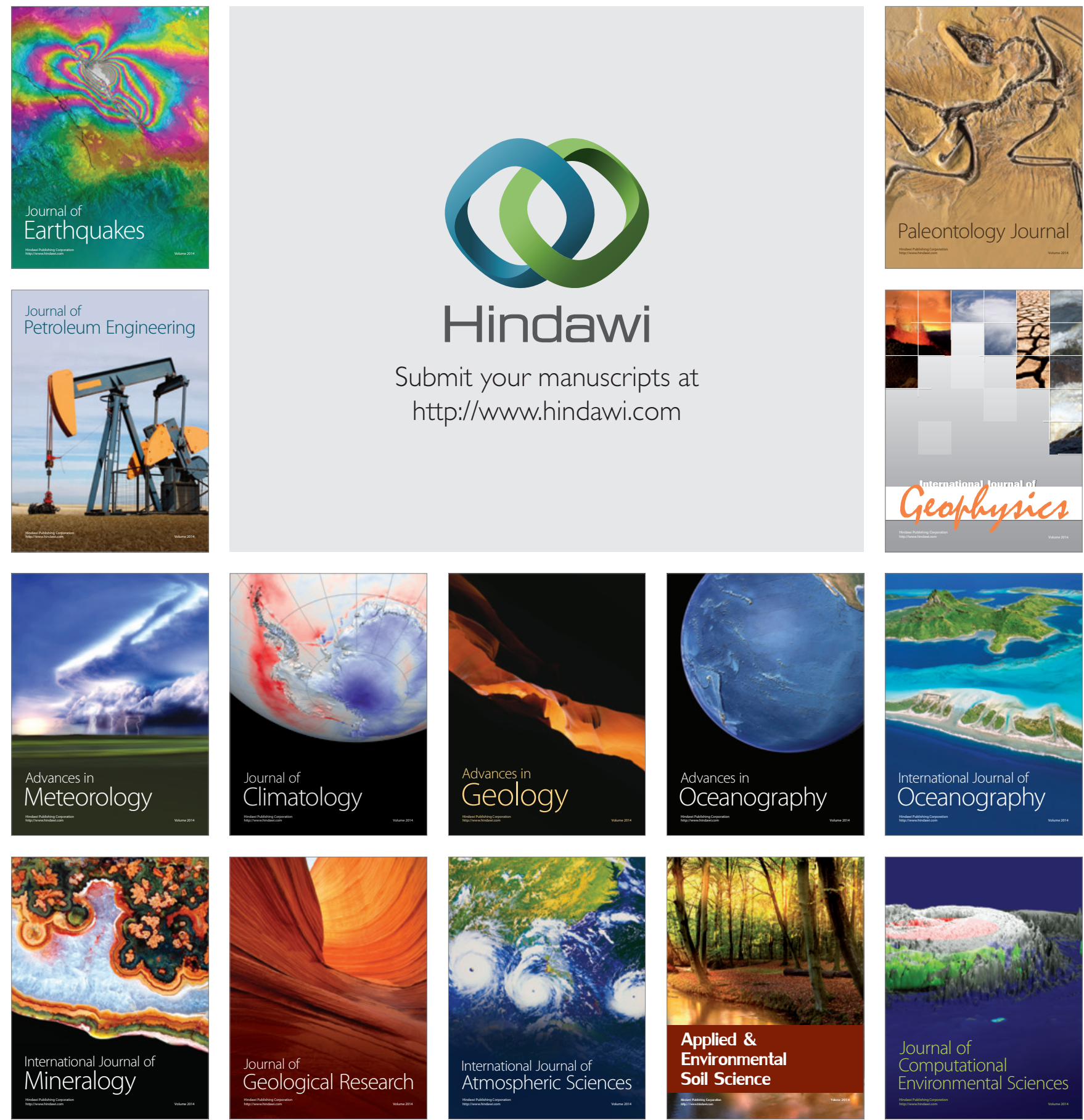